\title{
Role of PUF60 gene in Verheij syndrome: a case report of the first Chinese Han patient with a de novo pathogenic variant and review of the literature
}

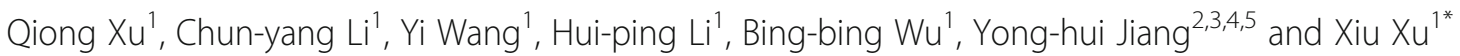

\begin{abstract}
Background: Verheij syndrome is a rare microdeletion syndrome of chromosome 8q24.3 that harbors PUF60, SCRIB, and NRBP2 genes. Subsequently, loss of function mutations in PUF60 have been found in children with clinical features significantly overlapping with Verheij.

Case presentation: Here we present the first Chinese Han patient with a de novo nonsense variant (c.1357C > T, p.GIn453*) in PUF60 by clinical whole exome sequencing. The 5-year-old boy presents with dysmorphic facial features, intellectual disability, and growth retardation but without apparent cardiac, renal, ocular, and spinal anomalies.
\end{abstract}

Conclusions: Our finding contributes to the understanding of the genotype and phenotype in PUF60 related disorder.

Keywords: PUF60, Verheij syndrome, Intellectual disability, Chinese Han patient

\section{Background}

Verheij syndrome (VRJS) (MIM 615583) is characterized by intellectual disability, growth retardation, dysmorphic facial features, and vertebral skeletal abnormalities. Additional features include coloboma and renal and cardiac defects [1-5]. Verheij syndrome is caused by a deletion in chromosome 8q24.3. The commonly deleted intervals include two genes, poly(U)-binding-splicing factor (PUF60) and scribbled planar cell polarity protein (SCRIB). Point mutations in PUF60 have been reported in individuals with clinical features overlapping with those associated with a 8q24.3 deletion or VRJS [2]. The PUF60 gene encodes a protein that directly interacts with splicing factor $3 \mathrm{~B}$, subunit 4 (SF3B4) and plays a role in the recognition of the 3' splice site and the recruitment of U2 and U5 small nucleolar ribonucleoprotein to the intron for splicing [2]. Mutations of the PUF60 gene including nonsense, frameshifting, splicing site, or missense have been identified in 24 individuals $[1,2,4-9]$. Here, we report a Chinese Han

\footnotetext{
* Correspondence: xuxiu@fudan.edu.cn

${ }^{1}$ Developmental and Behavioral Pediatric Department \& Child Health Care Department, Children's Hospital of Fudan University, 399 Wanyuan Road, Shanghai 201102, China

Full list of author information is available at the end of the article
}

patient who carries a heterozygous de novo and novel nonsense mutation (c.1357C > T, p.Gln453*) in PUF60 identified by clinical whole exome sequencing. This individual shares some characteristic features with previously described individuals including intellectual disability, growth retardation, and dysmorphic facial features but not other features such as cardiac, renal, ocular, and spine abnormalities [1, 2, 4-9]. This is the first report and characterization of a Chinese Han child harboring a PUF60 variant.

\section{Clinical summary}

A 5-year-old boy was born prematurely at 36 weeks of gestation without a known cause. The birthweight was $2650 \mathrm{~g}$ and appropriate for gestational age. He had a significant history of poor feeding and failure of thrive as an infant. At the age of 4 years and 7 months, his weight was $13.5 \mathrm{~kg}(<2 \mathrm{SD})$ and his height was $98 \mathrm{~cm}(<2 \mathrm{SD})$. His head circumference was $49.5 \mathrm{~cm} \quad(<1 \mathrm{SD})$. He showed global developmental delay and started to walk at the age of 20 months. At the age of 4 years, his vocabulary was limited to just a few words. At present, he is able to speak simple phrases but not complex sentences. In 
addition, he has significant history of chronic diarrhea from birth to 2.5 years of age without an identifiable cause. He had an average of 5-7 loose stools per day while being breastfed during the first year. Between the ages of 1-2.5 years, he was formula-fed and had an average of 68 loose stools per day. The chronic diarrhea resolved after 2.5 years of age without any clinical intervention. He was also diagnosed with febrile seizures and had significant sleep disturbance. Upon the physical examination at AGE, a distinct facial dimorphism was noted and these include a short neck, thin upper lip, long philtrum, wide nasal bridge, micrognathia, and almond-shaped eyes and short palpebral fissures (Fig. 1). There was no ocular coloboma and no shoulder subluxation or generalized joint laxity. Both parents were healthy and non-consanguineous. Family history was negative for any neurodevelopmental disorder or known genetic disease. Endocrine work-up, brain magnetic resonance imaging, abdominal and renal ultrasonography, and skeletal bone survey were normal. His hearing was normal. The detail clinical description of this patient and comparison with other previously reported cases carrying PUF60 mutations are listed in Table 1.

\section{Genetic evaluation}

Standard karyotyping was normal (46, XY). A clinical trio whole exome sequencing (WES) was performed by WuXi NextCODE Genomics, Shanghai, China (CLIA Lab ID: 99D2064856) using a previous described protocol [10]. Briefly, exome capture was performed using the Agilent SureSelect Human All Exon V5, Illumina TruSeq Rapid PE Cluster, and SBS kits (Agilent Technologies, Santa Clara, CA, USA). WES was performed on the Illumina HiSeq 2000/2500 platform. Reads were aligned to the human genome reference sequence (GRCh37/hg19 build of UCSC Genome Browser; http://genome.ucsc.edu) with the Burrows-Wheeler Aligner v.0.6.2. Duplicate paired-end reads were marked with Picard v.1.55 (https:// broadinstitute.github.io/picard/). The Genome Analysis Toolkit v.2.3-9 was used for base quality score recalibration, indel realignment, and variant discovery. Variants were annotated using a pipeline developed in-house [10] and filtered in the Exome Variant Server, gnomAD, Exome Aggregation Consortium, or the dbSNP databases. The candidate variants were confirmed by Sanger sequencing.

In this proband, a heterozygous de novo and nonsense c.1357C > T variant in exon 11 (NM_078480.2) was identified from the WES analysis and confirmed by Sanger sequencing. This variant is predicted to result in a premature stop codon (p.Gln453*) of PUF60 protein (Fig. 1). Other previously reported pathogenic variants are also diagramed in Fig. 2 for a comparison.

\section{Discussion and conclusion}

In this report, we presented the finding of a novel pathogenic variant in PUF60 gene in a Chinese child. To our knowledge, this is the first case of a Chinese child with PUF60 mutation. The proband's clinical presentations of intellectual disability, short stature, and dysmorphic facial features were similar with those previously reported cases with mutations in PUF60 variants or with a deletion of $8 \mathrm{q} 24.3$ containing the PUF60 or VRJS [1, 2, 4-9]. However, the vertebral anomaly, coloboma, renal defects, and cardiac defects reported in other cases were not found in our patient. In individuals with 8q24.3 deletion or VRJS, both PUF6O and SCRIB genes are deleted. In an early study in zebrafish, morpholino-mediated knockdown of either PUF60 or Scribble (Scrib) in zebrafish recapitulates some of the phenotypes of 8q24.3 deletion in humans [2]. Knockdown of either gene cause a short stature, microcephaly, and reduced jaw size.
A

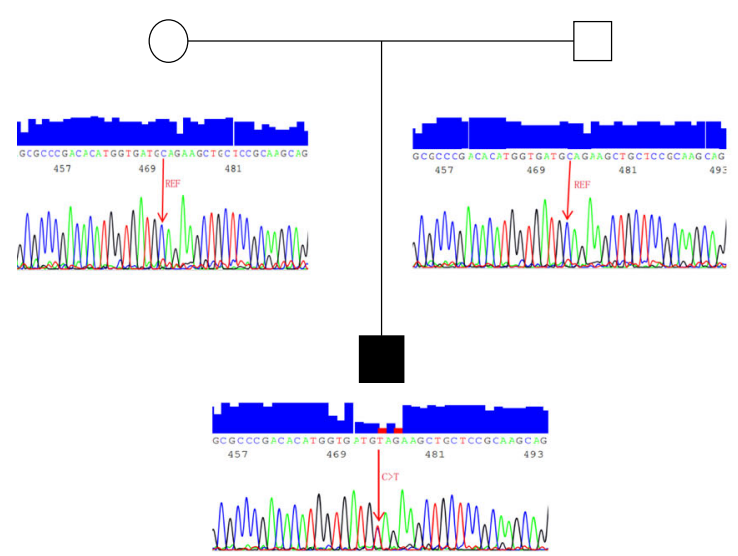

B

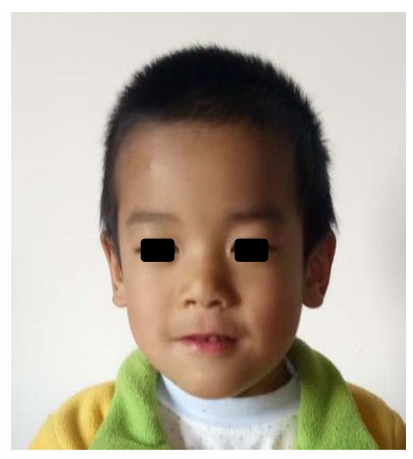

Fig. 1 A patient with a de novo heterozygous de novo PUF60 variant. a Sanger sequencing confirmation for c.1357C > T PUF60 variant in proband but absence in both parents. $\mathbf{b}$ A facial profile to patient. Noted for short neck, thin upper lip, long philtrum, micrognathia and wide nasal bridge, and narrow almond-shaped palpebral fissures 
Table 1 Comparison of clinical features in our patient and others previously reported with the PUF60 mutation

\begin{tabular}{|c|c|c|c|}
\hline Clinical phenotypes & Patient 1 & $\begin{array}{l}\text { Previous reported with } \\
\text { PUF60 variants } \\
(n=24)^{[2,4-9]}\end{array}$ & $\begin{array}{l}\text { Previous reported with } \\
8 \mathrm{q} 24.3 \text { deletion } \\
(n=7)^{[1,2]}\end{array}$ \\
\hline \multicolumn{4}{|l|}{ Gestation } \\
\hline Pre-term & + & $3 / 18$ & NA \\
\hline Full-term & & $15 / 18$ & $1 / 1$ \\
\hline Height (z score < 2 SD) & + & $16 / 23$ & $7 / 7$ \\
\hline Renal & - & $6 / 22$ & $4 / 7$ \\
\hline Coloboma & - & $8 / 23$ & $4 / 7$ \\
\hline Cardiac & - & $13 / 21$ & $5 / 7$ \\
\hline Skeletal & - & $15 / 23$ & $5 / 7$ \\
\hline Hand anomalies & - & $11 / 20$ & $4 / 7$ \\
\hline Joint laxity & - & $11 / 19$ & $5 / 7$ \\
\hline Feeding & + & $10 / 17$ & $5 / 7$ \\
\hline ID (intellectual disability) & + & $24 / 24$ & $5 / 6$ \\
\hline Auditory & - & $8 / 14$ & $1 / 5$ \\
\hline Hypertrichosis & - & $5 / 12$ & NA \\
\hline \multicolumn{4}{|l|}{ Facial feature } \\
\hline Long philtrum & + & $16 / 23$ & $7 / 7$ \\
\hline Thin upper lip & + & $15 / 23$ & $7 / 7$ \\
\hline Micro-retrognathism & + & $13 / 22$ & $4 / 7$ \\
\hline Short neck & + & $14 / 22$ & $5 / 7$ \\
\hline Wide nasal bridge & + & $9 / 22$ & $6 / 7$ \\
\hline
\end{tabular}
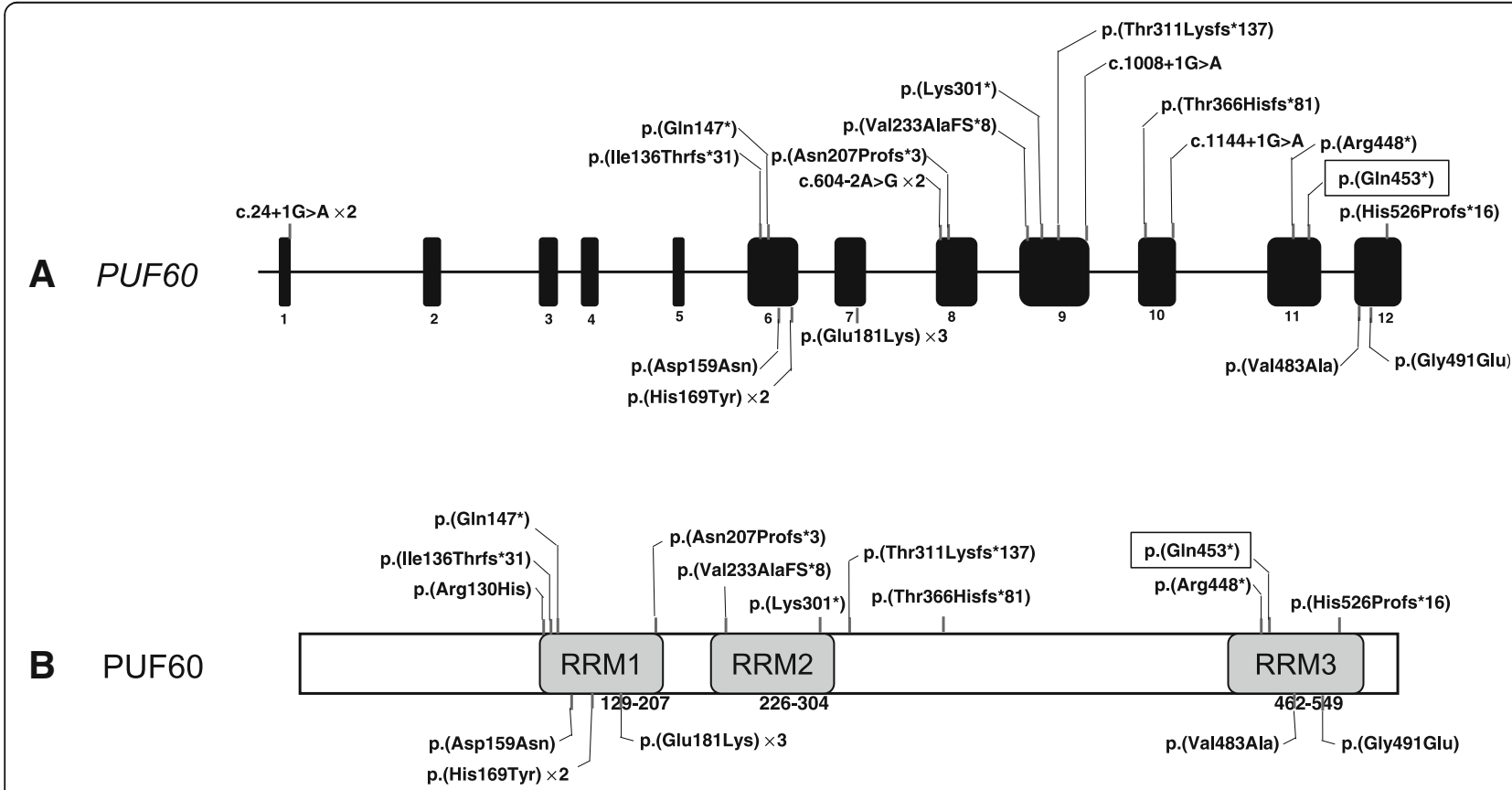

Fig. 2 Genetic location of the PUF60 variants identified to date. a Variants identified in PUF60 which are loss of function variants (stop codon, splicing and frameshift mutations) on top and missense variants below the gene. The variant reported in this case showed with square frame. We used bar to report the variants and " $x$ " represents the number of cases. The size of exon and intron is not proportional. $\mathbf{b}$ Distribution of amino acid changes related to the protein domains RRM, RNA recognition motif in PUF60 protein 
Knockdown of Scrib alone resulted in coloboma and renal abnormalities, whereas knockdown of PUF60 alone resulted in cardiac structural defects. Knockdown of both genes result in more severe short stature phenotype. It was concluded that PUF60 or SCRIB haploinsufficiency drives the majority of syndromic phenotypes found in patients with the copy number deletion of 8q24.3 or VRJS. However, several patients harboring PUF60 point mutations have been recently described, and these individuals have clinical phenotypes that overlap significantly with patients carrying 8q24.3 deletions. These findings support a major role for PUF60 in the phenotype of VRJS in human [1, 2, 4-9]. It remains to be seen whether mutations in SCRIB alone in humans may also cause the clinical problem similar to mutations of PUF60. The presentation of chronic diarrhea in our patient has not been previously reported $[1,2,4-9]$. It will be interesting to see if diarrhea is a feature of other patients harboring a PUF60 defect.

The findings of a heterozygous de novo nonsense change of PUF60 in our study further supports haploinsufficiency as the underlying mechanism [6]. Loss-of-function variants are predicted to result in altered dosages of different PUF60 isoforms and, consequently, abnormal splicing of targeted genes [2]. Both VRSJ syndrome and PUF60-related disorder encompass diverse phenotypes, suggesting that dysregulated targeted genes due to the PUF60 deficiency may account for diverse phenotypes in humans.

Interesting to note, two reports have suggested the overlapping clinical features between PUF60 related disorder with CHARGE syndrome. In these cases, the clinical and genetic evaluation of CHARGE syndrome is considered but the mutation study of $\mathrm{CHD7}$ is negative (PMID 29300383 and PMID: 28471317). Other have also suggested the overlapping feature between Cornelia de Lange syndrome and other craniofacial disorders caused by mutations in genes encoding the spliceosomal proteins $[11,12]$. The apparent question for the future investigation is whether there is a convergent molecular mechanism among these disorders.

The majority of genetic variants in PUF60 are predicted to be loss of function mutations, However, missense variants are also reported. Clinically, there is no significant difference between individuals carrying clear loss of function and missense variants. These may support the loss of function mechanism underlying the missense variants in these cases. However, additional phenotypical and molecular studies are warranted to clarify the genotype and phenotype correlation and whether the missense variants may result in loss of function at protein level.

This study is the first report of a Chinese Han patient carrying de novo PUF60 heterozygous mutation. The proband exhibited many of the characteristics previously reported in PUF60 variant or VRSJ patients such as intellectual disability, growth retardation, and dysmorphic facial features $[1,2,4-9]$. However, the patient did not present with especially vertebral skeletal abnormalities, coloboma, renal defects, or cardiac defects. Clinical and molecular characterization of patients with diverse background will help us better understand the genetic diversity and prevalence of PUF60 related disorder.

\section{Abbreviations \\ PUF60: Poly(U)-binding-splicing factor; SCRIB: Scribbled planar cell polarity protein; SF3B4: Splicing factor 3B, subunit 4}

\section{Acknowledgements}

We would like to thank the child and his parents whose participation made this study possible.

\section{Funding}

This study was funded by Shanghai Municipal Science and Technology Commission (grant number 15411967900) and by the National Science Foundation of China (grant number 81701496)

\section{Availability of data and materials}

The datasets used and/or analyzed during the current study are available from the corresponding author on reasonable request.

\section{Authors' contributions}

QX, CY, YH, XX conceived and conducted the study; QX, HP, XX identified the patients and carried out the clinical characterizations; CY, YW, BB carried out the molecular genetics studies; HP, YW, BB contributed WES analysis; QX, $\mathrm{YH}, \mathrm{XX}$ wrote the manuscript; all authors read and approved the final manuscript.

\section{Ethics approval and consent to participate}

This study was approved by the Ethics Committee of the Children's Hospital of Fudan University. Protocol Written informed consent was obtained from the patient's parents for the use of the patient's photograph and for WES

\section{Consent for publication}

Written informed consent was obtained from the patient for publication of this case report and accompanying images. A copy of the written consent is available for review by the Editor-in-Chief of this journal.

\section{Competing interests}

The authors declare that they have no competing interest.

\section{Publisher's Note}

Springer Nature remains neutral with regard to jurisdictional claims in published maps and institutional affiliations.

\section{Author details}

${ }^{1}$ Developmental and Behavioral Pediatric Department \& Child Health Care Department, Children's Hospital of Fudan University, 399 Wanyuan Road, Shanghai 201102, China. ${ }^{2}$ Department of Pediatrics, Duke University School of Medicine, Durham, NC 27710, USA. ${ }^{3}$ Department of Neurobiology, Duke University School of Medicine, Durham, NC 27710, USA. ${ }^{4}$ Program in Genetics and Genomics, Duke University School of Medicine, Durham, NC 27710, USA ${ }^{5}$ Cellular Molecular Biology, Duke University School of Medicine, Durham, NC 27710, USA

Received: 27 July 2018 Accepted: 12 October 2018

Published online: 23 October 2018

\section{References}

1. Verheij JB, de Munnik SA, Dijkhuizen T, de Leeuw N, Olde Weghuis D, van den Hoek GJ, Rijlaarsdam RS, Thomasse YE, Dikkers FG, Marcelis CL, et al. An $8.35 \mathrm{Mb}$ overlapping interstitial deletion of $8 \mathrm{q} 24$ in two patients with coloboma, congenital heart defect, limb abnormalities, psychomotor retardation and convulsions. Eur J Med Genet. 2009;52(5):353-7. 
2. Dauber A, Golzio C, Guenot C, Jodelka FM, Kibaek M, Kjaergaard S, Leheup B, Martinet D, Nowaczyk MJ, Rosenfeld JA, et al. SCRIB and PUF60 are primary drivers of the multisystemic phenotypes of the 8q24.3 copynumber variant. Am J Hum Genet. 2013;93(5):798-811.

3. Fiorentino DF, Presby M, Baer AN, Petri M, Rieger KE, Soloski M, Rosen A, Mammen AL, Christopher-Stine L, Casciola-Rosen L. PUF60: a prominent new target of the autoimmune response in dermatomyositis and Sjogren's syndrome. Ann Rheum Dis. 2016;75(6):1145-51.

4. Low KJ, Ansari M, Abou Jamra R, Clarke A, El Chehadeh S, FitzPatrick DR, Greenslade M, Henderson A, Hurst J, Keller K, et al. PUF60 variants cause a syndrome of ID, short stature, microcephaly, coloboma, craniofacial, cardiac, renal and spinal features. Eur J Hum Genet. 2017;25(5):552-9.

5. Santos-Simarro F, Vallespin E, Del Pozo A, Ibanez K, Silla JC, Fernandez L, Nevado J, Gonzalez-Pecellin H, Montano VEF, Martin R, et al. Eye coloboma and complex cardiac malformations belong to the clinical spectrum of PUF60 variants. Clin Genet. 2017:92(3):350-1.

6. El Chehadeh S, Kerstjens-Frederikse WS, Thevenon J, Kuentz P, Bruel AL, Thauvin-Robinet C, Bensignor C, Dollfus H, Laugel V, Riviere JB, et al. Dominant variants in the splicing factor PUF60 cause a recognizable syndrome with intellectual disability, heart defects and short stature. Eur J Hum Genet. 2016;25(1):43-51.

7. Graziano C, Gusson E, Severi G, Isidori F, Wischmeijer A, Brugnara M, Seri M, Rossi C. A de novo PUF60 mutation in a child with a syndromic form of coloboma and persistent fetal vasculature. Ophthalmic Genet. 2017;38(6): $590-2$.

8. Zhao JJ, Halvardson J, Zander CS, Zaghlool A, Georgii-Hemming P, Mansson E, Brandberg G, Savmarker HE, Frykholm C, Kuchinskaya E, et al. Exome sequencing reveals NAA15 and PUF60 as candidate genes associated with intellectual disability. Am J Med Genet B Neuropsychiatr Genet. 2018;177(1): 10-20.9.

9. Moccia A, Srivastava A, Skidmore JM, Bernat JA, Wheeler M, Chong JX, Nickerson D, Bamshad M, Hefner MA, Martin DM, et al. Genetic analysis of CHARGE syndrome identifies overlapping molecular biology. Genet Med. 2018. https://doi.org/10.1038/gim.2017.233. [Epub ahead of print].

10. Yang L, Kong Y, Dong X, Hu L, Lin Y, Chen X, Ni Q, Lu Y, Wu B, Wang H, et al. Clinical and genetic spectrum of a large cohort of children with epilepsy in China. Genet Med. 2018. https://doi.org/10.1038/s41436-018-0091-8. [Epub ahead of print].

11. Lehalle D, Wieczorek D, Zechi-Ceide RM, Passos-Bueno MR, Lyonnet S, Amiel J, Gordon CT. A review of craniofacial disorders caused by spliceosomal defects. Clin Genet. 2015;88(5):405-15.

12. Hastings ML, Allemand E, Duelli DM, Myers MP, Krainer AR. Control of premRNA splicing by the general splicing factors PUF60 and U2AF(65). PLoS One. 2007:2(6):e538.

Ready to submit your research? Choose BMC and benefit from:

- fast, convenient online submission

- thorough peer review by experienced researchers in your field

- rapid publication on acceptance

- support for research data, including large and complex data types

- gold Open Access which fosters wider collaboration and increased citations

- maximum visibility for your research: over $100 \mathrm{M}$ website views per year

At $\mathrm{BMC}$, research is always in progress.

Learn more biomedcentral.com/submissions 